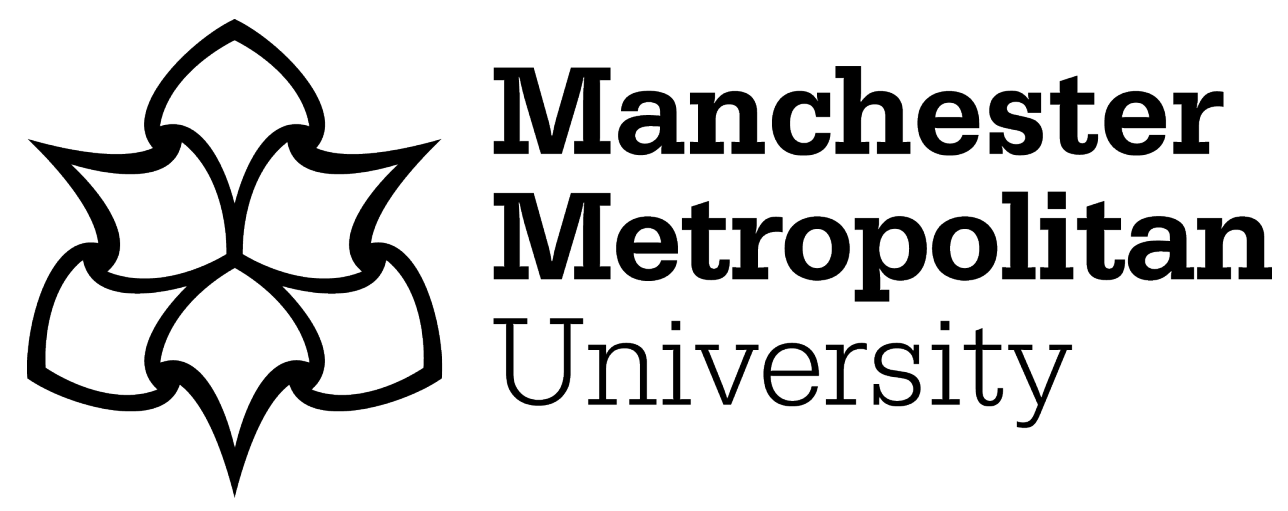

Schröder, Patrick, Bengtsson, Magnus, Cohen, Maurie, Dewick, Paul ORCID logoORCID: https://orcid.org/0000-0002-1176-2292, Hoffstetter, Joerg and Sarkis, Joseph (2019) Degrowth within - Aligning circular economy and strong sustainability narratives. Resources, Conservation and Recycling, 146. pp. 190-191. ISSN 0921-3449

Downloaded from: https://e-space.mmu.ac.uk/622756/

Version: Accepted Version

Publisher: Elsevier

DOI: https://doi.org/10.1016/j.resconrec.2019.03.038

Usage rights: Creative Commons: Attribution-Noncommercial-No Derivative Works 4.0

Please cite the published version 


\title{
Degrowth within - Aligning circular economy and strong sustainability narratives
}

\author{
Patrick Schröder ${ }^{a}$, Magnus Bengtsson ${ }^{b}$, Maurie Cohen ${ }^{c}$, Paul Dewick ${ }^{d}$, Joerg Hoffstetter ${ }^{\mathrm{e}}$, \\ Joseph Sarkis ${ }^{f}$ \\ a Institute of Development Studies, University of Sussex, UK \\ b Independent Researcher, Japan \\ c New Jersey Institute of Technology, USA \\ d Manchester Metropolitan University and Manchester Institute of Innovation Research, The \\ University of Manchester, UK e KEDGE Business School, Bordeaux, France \\ $f$ Foisie School of Business, Worchester Polytechnic Institute, USA
}

Published in Resources, Conservation and Recycling, 146 (2019) 190-191, https://doi.org/10.1016/j.resconrec.2019.03.038

\begin{abstract}
This perspective calls for building greater understanding of overlapping and conflicting considerations between the sustainability principles that inform current conceptions of circular economy and degrowth. We contend that scholars and practitioners need to be pragmatic and to recognize evident ideological differences, but simultaneously to acknowledge beneficial similarities and complements. The common aim of both frameworks - to change business-as-usual and to enable human society to operate within ecological planetary boundaries - will likely engender opportunities to formulate new solutions. Management of the inherent tensions, such as the scale and scope of rebound effects, will continue to pose challenges. However, with thoughtful dialogue, commitment to respectful discourse, and more refined articulation we are confident that progress will be made. By building on synergies and seeking holistic strategies, the academic community, along with its transdisciplinary partners, can advance strong global sustainability efforts.
\end{abstract}

\section{Perspective}

The circular economy concept is gaining traction among policy- makers and major businesses in Europe, China and elsewhere around the world, and has the potential to emerge as a new sustainability paradigm. It has also given rise to a number of incisive critiques pointing out its shortcomings. In short, the circular economy as a policy and business practice has over the past few years become a contested concept (Korhonen et al., 2018).

While there is some agreement on the means and goals of the circular economy, there are many remaining issues that have yet to be fully resolved. There is no agreement on the exact definition leaving open questions about the social dimension of the circular economy and how it might affect, for example, inequality, power relations in corporate value chains, the role and rights of consumers, users and citizens (and how to protect them), and the distribution of resources and exploitation of labour. There is uncertainty on units of analysis and metrics for capturing the transition dynamics from a linear to a more circular model. Questions about how to avoid lock-ins and deal with trade-offs are unresolved. The extent to which the emergence of the circular economy is constrained by the context of neoliberal economic growth and the ideology of consumerism is underplayed. And, most importantly, it is not clear that a circular economy can deliver global sustainability where human needs can be met within the planetary boundaries. 
The fault lines of the debate are not new. There are proponents of 'strong' sustainability and degrowth approaches. This school of thought aims for radical political and economic reorganization and social transformation leading to reduced resource and energy use (Kallis et al., 2018). This perspective can be quick to dismiss the circular economy as simply an alternative green growth model. To this group, the circular economy is an insufficient solution to achieve global sustainability within the Earth's ecological limits.

We argue that a demarcation presenting the circular economy vs. strong sustainability or degrowth is a false dichotomy. It is also un- helpful to advance global sustainability efforts. Instead of trying to di- vide the two sustainability measures, understanding the similarities is also important.

Circular economy and degrowth share a number of important principles and goals, despite the existence of nonnegligible differences (Ghisellini et al., 2016). To solve our planet's anthropogenic ecological crisis it is necessary to focus on the common aim of both approaches - for human society to operate within the ecological limits of the planet, contrary to business-as-usual. The circular economy can be defined as "restorative and regenerative by design", in contrast to the current extractive linear model. The circular economy also links to the concept of 'regenerative eco-innovation', defined as those eco-innovations that 'restore, renew, revitalise' natural systems. It contributes new technologies, new organisational approaches, new business and supply chain models into the economy in a way that maximises value from asset and material stocks. Much of the structural waste in durable products, mobility, food, and the built environment offers economic opportunities: achieving growth within (Ellen MacArthur Foundation, 2015).

There are also important degrowth elements within the circular economy narrative. These elements - at least in some versions of the circular economy - underscore the need for narrowing and slowing material flows, in addition to increasing circularity. In the long-term, there is a creative destruction - an industrial structural change - element of a transformation toward the circular economy. For example, the goal of the circular economy is to have extractive linear sectors of the economy shrink substantially. In particular, mining and fossil fuel de- pendent industries will need to constrict. These will be replaced with regenerative industries meant to restore the Earth's ecosystems while generating value.

One way of characterising the difference between the circular economy and degrowth, but also to show how they could complement each other, is how they address the three major determinants of environmental impact as identified in the IPAT equation where environ- mental impact $(I)$ is a function of population $(P)$, affluence $(A)$, and technology $(T)$ (Zhang et al., 2018). Degrowth tends to focus on affluence. The circular economy tends to concentrate on technological improvements. The degrowth community pays less attention to techno- logical innovation and argues that technological solutions are inadequate and insufficient for dealing with the multiple unfolding ecological crises. Proponents of the circular economy tend to be much more optimistic with regards to innovation and technology. The IPAT equation also highlights a blind spot that circular economy and de- growth have in common: continued global population growth. Given the urgency of curbing humanity's impact on the planet, a need exists to address each of these three drivers.

One unresolved issue for the circular economy is the potential re- bound effect - also known as Jevon's Paradox. The rebound effect operates at multiple economic levels where improvements in efficiency due to technology are offset by growth in usage. For example, increased recycling boosts the supply of relatively cheap secondary materials, lowering prices 
and spurring more consumption of products made of these materials. In the circular economy, the rebound effect is expected to lessen over time as more goods and services meet 'circularity' aspirations and as the economy becomes more service-oriented.

The circular economy and its concepts are still emerging and require further refinement toward resolving the aforementioned issues. More empirical evidence is needed about the practical challenges for industry and policy makers involved in charting a pathway toward a more circular economy. In the process of addressing these knowledge gaps, the degrowth theoretical framework can be useful to provide relevant in- sights for the circular economy. That is, degrowth can and should contribute to circular economy principles, as circular economic principles can contribute to an anchoring of degrowth commitments in an inescapably resource-dependent world.

Implementing a circular economy, degrowth or any other approach to sustainability without remnants and legacies of other social and economic systems in place is unlikely and fancifully utopian. Where in the vast materials economy can construction of new out of the old occur? Science and experimentation need to play roles. We need to do our best to understand the consequences of circular economy programmes and activities, both intended and unintended, untapped opportunities and barriers to realising these opportunities.

Finally, we would like to emphasise the need to be pragmatic. It is not realistic to expect circular economy, degrowth or for that matter any sustainability philosophy to be all encompassing. Each conception and action will have limitations, blind angles, and unintended con- sequences. What is important is awareness of these limitations; and to explore how different approaches can build synergies through holistic strategies. In this regard the academic community, along with its transdisciplinary partners, plays an important role.

\section{References}

Ellen MacArthur Foundation, 2015. Growth Within - A Circular Economy Vision for a Competitive Europe. Cowes, Isle of Wight, UK.

Ghisellini, P., Cialani, C., Ulgiati, S., 2016. A review on circular economy: the expected transition to a balanced interplay of environmental and economic systems. J. Clean. Prod. 114, 11-32.

Kallis, G., Kostakis, V., Lange, S., Muraca, B., Paulson, S., Schmelzer, M., 2018. Research on degrowth. Annu. Rev. Environ. Resour. 43 (October (17)), 291-316.

Korhonen, J., Nuur, K., Feldmann, A., Birkie, S., 2018. Circular economy as an essentially contested concept. J. Clean. Prod. 175, 544-552.

Zhang, C., Chen, W.Q., Ruth, M., 2018. Measuring material efficiency: a review of the historical evolution of indicators, methodologies and findings. Resour. Conserv. Recycl. 132, 79-92. 